\title{
Bringing Life to Research: Life History Research and ESL
}

Sandra G. Kouritzin

Despite its potential, life history methodology has seldom been used in TESL research. This article first defines what is meant by life history research methodology, and then examines how it might benefit our research in TESL. Answering the question, What are the benefits of life history research? the author examines how life histories in other fields and in her own research have shifted focus from the extraordinary to the mundane, and from the universal to the singular, while simultaneously adding previously marginalized perspectives, challenging and informing theory, allowing for comprehensive reinterpretation, locating research historically, and encouraging the production of invitational texts. The author further argues that participants in life history research benefit from being listened to and from framing their stories in terms of overcoming adversity, while the researcher benefits from becoming critically involved with her or his participants. The final section of the article addresses some of the potential pitfalls of life history research, including reliability, verifiability, the tendency toward exoticism, difficulties with translation and authorship, and the "afterlife" of research. The article concludes by asserting that life history is one methodology that is powerful enough to begin recording the complexities of race, class, language, history, and cultures in our classrooms.

\section{Introduction}

Sometimes I watch Oprah. I also read the news. Not being particularly interested in mergers or acquisitions, political maneuvers, or dirty tricks, I instead follow the unfolding of information about murders, abductions, accidental deaths, right-to-die, harassment, and sexual deviance. In so doing I am always amazed by the willingness of people, victims and victimizers alike, to talk about their perceptions, experiences, and justifications, and I am frequently puzzled by the conventional explanations: "I am doing this so that other people won't suffer in the future"; "I have known neglect and abuse throughout my life"; "I didn't know it was wrong."

Much is revealed in these kinds of statements. These are statements about causality, and, true or not, the structure of these statements explains a lot about the kind of society we live in. If Oprah has taught me anything in our years together, it is that many people want to have their stories told and to explain their behavior in terms of their own subjectivities. 
My appetite for details in the morning newspaper is testimony to another phenomenon. I consume people's subjective life histories in an effort to elucidate their present circumstances and perhaps learn something about myself. Therein lies the alchemical appeal of life history research: it is accessible and grounded in everyday meaning.

\section{What is Life History Research?}

\section{Life History: The Accessible Outcast}

The life history has been called a "common denominator" in social science research because our customary framework for analyzing others is "in what way is this person like, or unlike, myself?" (Frank, 1979, p. 73). In this way we are all social scientists, understanding others in terms of those narrated biographical "chunks" to which we are privy, and then curling, intertwining our lives within and among them. Social science researchers collecting life histories go beyond what we all do in that they bring more multidimensional considerations to this common social practice, to engage in what BertauxWiame (1981) calls "listening beyond," meaning "trying to hear, beyond the words of a given person, the speech of a social culture" (p. 260).

Yet despite the accessibility, usefulness, and potential significance of life history research, until fairly recently it has often been neglected, or even rejected, in serious academic inquiry (Bertaux, 1981a; Fischer, 1983; Morin, 1982; Watson, 1976). This neglect has more recently been countered, particularly by: (a) feminist researchers concerned with writing/righting women's histories (Middleton, 1992a, 1992b; Reinharz, 1994; Stacey, 1991); (b) those researchers concerned with recording disappearing ways of life (Bertaux \& Bertaux-Wiame, 1981; Cruikshank, 1990); and (c) academics exploring the experiential diversity of disenfranchised or marginalized groups (Goodson, 1992; Smith, 1994); but not so much by researchers in education. ${ }^{1}$ In fact, many recent educational methodology texts devote little space to life history research (Delamont, 1992; Stake, 1995; Van Manen, 1992; Yin, 1994) or may not mention it at all (McMillan \& Schumacher, 1989; Nunan, 1992).

In an effort to advance the use of life history narratives in educational research, this article looks at what has been revealed on those occasions when such approaches have been employed in the social sciences. After first discussing what is meant by life history, both in terms of "doing" and writing research, I answer two questions: (a) What have been the benefits of life history research? and (b) What are the potential pitfalls of life history research? Each of these questions is answered with regard to (a) theory and research (i.e., the construction of knowledge), (b) the participants, and (c) the researcher. I pay particular attention to the implications for English-as-aSecond-Language (ESL) research practice, where life history has been employed in a limited way, where my own research interests are located, and 
where, because of rapidly-changing demographics, educational research in general is beginning to focus.

\section{The Academic Shelf Life}

Perhaps owing to academic rejection, life history methodological considerations in the past often began by examining the life history of the life history form, as if lineage might lend legitimacy (Frank, 1979; Kaplan, 1982; Morin, 1982; Shaw, 1980). In such texts it is generally acknowledged that the Chicago School in the 1920s represented a golden era of life history research, perhaps overfocused on deviance (Bertaux \& Kohli, 1984), after which nothing much was done. According to Kaplan (1982) it was the nature of Chicago, a city that grew 100-fold in 50 years as "waves of immigrants collided with newly emerging corporate capitalists" (p. 34), which led to the development and subsequent popularity of the method. This historical context is noteworthy because life history research, like ESL, is the progeny of the immigrant experience. $^{2}$

Before looking at the contributions of life history research, both past and potential, it is useful to define life history research, keeping in mind that there is no recognized consensus. At least one life history has been described as "an epic of peasant life ... an ethnographic description of a culture ... an intimate social history of the Third Republic ... a case study in the quarrel over ethnicity ... an account of a childhood [and] ... a gripping tale" (Morin, 1982 , p. 5). I at least have heard no other research endeavor described in quite this way.

\section{Life History Defined}

Depending on our background and interests, we may think of life history as:

1. a theoretical and methodological research frame (Bertaux, 1981a;

Denzin, 1989; 1994; Gluck \& Patai, 1991; Josselson, 1995; Josselson \&

Lieblich, 1993; Kirby \& McKenna, 1989; Lieblich \& Josselson, 1994;

Lincoln \& Denzin, 1994; Middleton, 1992b);

2. a type of social science interview (Delamont, 1992);

3. the topic or technique used in obtaining linguistic samples (fairly common in the ESL context);

4. a pedagogical approach drawing on life experiences (Butler \& Bentley, 1992); or,

5. a specific type of measurable variable (e.g., years of education, socioeconomic status, place of birth, length of residence in Canada).

In this article the concern is with the first two categories, when the life history is the focus and purpose of research, rather than when it is used as the means to another end.

In these two contexts the life history must be operationalized as more than a life story. Life history comes to mean an aggregate of documents, including an oral life story, centering around and supporting a life narrative, 
and possibly incorporating many of the terms it is sometimes considered synonymous with: oral autobiographies, biographies, memoirs, journals, dream analyses, diaries, personal documents, case histories, oral accounts, testimonies, personal histories, individual documentaries, confessions, thirdparty reports. Although some researchers claim that life histories present the experiences and interpretations held by an individual or collective (Shaw, 1980), such definitions could be criticized for their lack of emphasis on critical interpretive inquiry, seemingly suggesting that life histories are little more than a collection of oral and written documents knitted into a coherent narrative, and told from an emic perspective. In fact life history has often been seen as self-evident, able to speak for itself (Frank, 1979) ${ }^{3}$ in much the same way that biography does. Such understandings privilege the collection of the data over its analysis, failing to keep in mind that the collection of life histories is not a technique, but a methodology, and also failing to distinguish research from journalism.

A better understanding can be gained by viewing the life history as a particular type of case study (Yin, 1994; Stake, 1995). Where a life history is different from a case study is in the definition of what constitutes a context, the uses made of multiple sources of evidence, and the privileging of individuals' understandings of a phenomenon over the phenomenon itself. As in case study inquiry, extensive analyses, triangulation of sources, complexity, and final textual form are central to the development of rigorous academic research.

Although the case study might be concerned with documenting the immediate physical and emotional context, and may do so over time, life history research focuses on individuals' understanding and recollection of events that have had a substantial impact on their development. Documenting a life history also entails triangulation in order to understand what has been omitted from, and what subjective meaning given to, narrated events. It is not the events themselves that are of greatest importance, but the participants' understandings of the events and their later impact on, or resolution in, the participants' lives. In other words, the truth that participants tell "can be quite different from the 'historical truth' of what happened in their lives, but nevertheless it has a force in their attitudes and actions" (Measor \& Sikes, 1992, p. 224).

To achieve these ends, the life history may employ (a) oral accounts of the participant's life narrated by the participant, (b) interview data used to flesh out and aid in understanding the oral history, (c) any available documents (e.g., diaries, letters, school records, legal papers, news clippings) corroborating or contradicting the narrator's life events, (d) third-party interviews with other persons to provide additional information or alternative interpretations, ${ }^{4}$ (e) reference and comparison with other research and examples, and (f) analysis and comparison across the different sources. These can roughly 
be categorized as three orders of data: the first-party report ( $a \& b)$, the third-party report ( $c \& d$ ), and the researcher report (e \& f), with the nucleus being an oral life story narration.

\section{"Truth" in Life History Narratives}

According to research on narrative knowing, we know ourselves only as we are able to make coherent narrative sense and order of the events of our lives (Denzin, 1986; Freeman, 1984; Ochberg, 1988; Polkinghorne, 1991). By understanding ourselves in narrative, as always living in the midst of a yet-to-becompleted story, we see ourselves both in the process of continuously becoming and in a state of being. Such understandings shake up the conceptions we might have of truth in social science research. For example, in my research with people who have lost a childhood first language while learning a dominant second language, I have found that participants may talk of overcoming the disadvantage of not speaking the first language (self as hero) on one occasion and of having their language stolen (self as victim) on another. Each narration casts a different light on the same series of events. Neither is true; nor is either false. The narrative form represents not only individual understandings, but also the prevailing culture of the interview itself.

Fine (1994) speaks of the same honestly contradictory narrative. She explains that her adopted (into a white middle-class family) adolescent Latina niece had been arrested for shoplifting and subsequently sexually assaulted by the department store security officer. The family was concerned with how Jackie might represent herself in the legal system, yet, as Fine writes:

She slid from victim to survivor, from naive to coy, from deeply experienced young woman to child. In her deposition she dismantled the very categories I so worried we had constructed as sedimented pillars around her, and she wandered among them, pivoting her identity, her self-representations, and, therefore, her audiences. She became neither the Other nor the Same. Not even zippered ... But she would better be viewed as an honest narrator of multiple poststructural selves speaking among themselves, in front of an audience searching relentlessly for pigeonholes. (p. 71)

Always living in the midst of a yet-to-be-completed story in which we will live out the consequences of our multiple selves and ideal selves, always with a view to the audience(s) and their multiple selves, we not only cannot expect one "truth" to be represented, we should be suspicious if we happen to find one.

\section{The Oral Narration of Life Histories}

The emphasis on oral narration has particular importance in life history because it necessitates the presence of an Other who both summons the 
performance of storytelling and collaborates in conjuring the context. In an oral exchange the narrative is not fully rehearsed in the narrator's head (Frank, 1979) waiting to be recited. The life story is instead created in the "interlanguage between," ${ }^{5}$ that is, in the co-constructed dialogue between the narrator and the researcher. Because neither the researcher nor the narrator knows what will happen between them during narration, that is, they cannot control beforehand "what emotions will be evoked, what illusions shattered" (Ortiz, 1985, p. 104), what rhapsodies invoked, what disclosures sung, whither they will dance, successful life history interviews have fairly equitable power relations. Of necessity, therefore, the relationship between the researcher and the researched must be characterized by trust and responsibility. ${ }^{6}$

Although researchers such as Measor and Sikes (1992) have analyzed their own life history research with teachers and have critiqued the power relationships in the "research bargains" into which they entered, their arguments are post hoc, that is, resulting from things that they failed to consider from the outset. Examining their research, Measor and Sikes explain that the relationship between researcher and researched becomes one of friendship, togetherness, trust, and pursuit of a common goal, a relationship that progresses over the course of the project. They then cite a number of caveats to the trusting relationships they entered into, including that (a) the relationships were initiated by the researcher; (b) the research agenda, sampling procedures, and time required were not sufficiently explicated; (c) the research relationships were aimed at getting data; therefore, none of the friendships was maintained after this objective was reached; (d) personal disclosures on the part of the researchers were used in an exploitive manner, invoked only in order to gain more details; and finally (e) the interviews were artificial social constructs that "flagrantly disregard[ed the] rules of conversational discourse" (p. 214). It is my position that none of these need have an adverse affect on the trust and responsibility developed in the research process provided they are considered by the researcher before beginning the research. I address each of these caveats in turn.

First, in my research on first language loss, I initiated my relationships with the research participants through a published call for volunteers, but the research participants chose their own time, place, and medium to contact me. I began the negotiation for a convenient meeting time and place, but is this artificial? As a person who values personal connection, I find that my role is often that of initiator in my family relationships and friendships. Second, I explained the nature of the study, my own biases and investment in the project, the procedure I would follow in each interview, the uses of the data, the considerable time commitment, the nature of our relationship, and what they could expect from me. I gave them access to the proposal for the research, the ethical review forms, and any research articles that they 
wanted. We discussed whether they would like to receive a small honorarium (if they refused, that money was donated to a local food bank). We discussed up front what should be done with any royalties if my research were published as a book. We discussed whether they wanted to engage in member checks, ${ }^{7}$ read the research, and / or attend any public lectures I might present about first language loss. They were given copies of the transcripts of every interview, and they were offered one of the two audiotapes I made of every interview. This took time, but certainly less time than dealing with any of these things in an after-the-fact manner. Third, based on the participants' responses in these discussions, I did or did not maintain relationships with them. Since the time of my interviews, I have written two letters of reference for academic study, given advice on or edited several articles or papers, enjoyed a guest lecture and poetry reading by one of the participants in a class that I was teaching, followed up with two participants over coffee, and, most recently, was approached for advice and input by one participant who would like to spearhead the development of resource book for parents on strategies to maintain first languages. I am involved, if peripherally, in their lives. Fourth, I do not make too much distinction between my personal and my public life. I tried to approach the research with humanity for the participants when they were living their stories, humor in the situations they recounted, and humility about my own ability to effect change. ${ }^{8}$ By chance, through a traumatic late miscarriage and the anxious, mostly bedridden nine months before the birth of my daughter, I also discovered the need for my own vulnerability to become part of the research process. The narrators trusted me more because of my situation, but by their kindness and compassion, they ensured that I would never knowingly misrepresent or harm them. Fifth and finally, I made no pretense that we were having "conversations," but rather explained my own understanding of the word interview, a word that I see as capturing the notion of a negotiated space between two people, one requiring effort from the narrator and the listener, and one symbolically represented by the Japanese characters that mean "face-touching" (Kouritzin, 1999).

\section{The Meaning of "Life" in Life History}

As a final note, the designation life history may be misleading because it implies that the story encompasses a lifetime when it may center on a particular time frame, event, or focus. In fact, although it may sometimes be appropriate to ask only one question-"Please tell me the story of your life" - in most instances the researcher begins with an intent in mind, making the life history a "briefer, more focused biograph[y]" (Smith, 1994, p. 287) than the entire story of one's life. For example, researchers may have a particular interest in educational disenfranchisement (Wolcott, 1983), the resistance of socially ascribed identity (Borland, 1991), the symbolic repre- 
sentation of a particular geographical place (Chanfrault-Duchet, 1991), historical views of women's volunteer work in Montana (Mercier \& Murphy, 1991), the intergenerational effects of the Holocaust on survivors' families (Bar-On \& Gilad, 1994), or the linguistic forms and narrative genres used to represent the life course within and/or across (sub)cultures (Hankiss, 1981; Hofer \& Niedermüller, 1988; Linde, 1993; Luborsky, 1987; Ochberg, 1988). In my own research I have employed life history methods: (a) to explore the experiences of immigrant mothers, especially with regard to language learning (Kouritzin, 1994, in press); and (b) to understand in a personal, descriptive, narrative way, the experience of first language (i.e., mother tongue) loss (Kouritzin, 1997, 1999).

\section{What Have Been the Benefits of Life History Research?}

Theoretical arguments advocating the use of life history research are often written in reaction against quantitative methodologies, in particular the sociological survey. Bertaux (1981b), for example, rejects his prior survey research with his opening claim that "once I was a positivist" but now I have recovered (p. 29), and then claims that survey research, being steeped in positivism, offers little more than a description of the relationship between variables.

More recently, Cohler (1991) has reframed this kind of argument. Instead of mounting an attack against quantification (offense), he has begun defending life history research against claims that it is unscientific (defense). $\mathrm{He}$ does so in such a way that the unique potential of life history research is highlighted:

Emphasis on rationalist assumptions has led some to disregard the life story as a narrative presentation of disparate experiences uniquely patterned or organized in ways not always accessible to the logical, experimental-predictive test valued by "normal," experimental, psychological science.... Focus on rhetoric, or means used to realize coherence, including the way the story is told, has been overlooked in the emergence of a substantively rational, experimental, psychological science emphasizing verification, predictability, and emphasis on continuity rather than change within lives over time. (p. 176)

This redistributed emphasis allows for a both/and rather than an either/or approach to life history research. In this orientation we are able to examine how life history can augment standard research practices instead of why it must replace them.

\section{Benefits for Theory and Research}

This section stresses what can be learned from the analysis of life histories, the benefits for theory and research, drawing examples both from my re- 
search on language loss and from other published studies. The following section then considers the reflection and transformation that results from critical involvement with life history research, by which is meant the benefits for the participants.

Voices from the chorus. Perhaps the most important contribution of life history research is its shift in focus from the extraordinary to the mundane, with a concurrent shift from the universal to the singular. Traditionally, although the (in)famous and powerful have had their extraordinary and singular histories recorded for posterity, every(wo)man has had her or his story told as part of a mundane and universal collective in terms of averages, means, and standard deviations.

Benjamin (1968), in Illuminations, speaks of a German tale entitled "Unexpected Reunion" by Johann Peter Hebel. It is the story of a young miner who on the eve of his wedding dies in a mine tunnel. His intended bride remains faithful and lives to a great age. Near the end of her life, his body, having been preserved by iron vitriol, is recovered from the mine and she recognizes her beloved. She then dies. Benjamin explains that, faced with the necessity of covering a long period of years, Hebel wrote:

In the meantime the city of Lisbon was destroyed by an earthquake, and the Seven Years War came and went, and Emperor Francis I died, and the Jesuit Order was abolished, and Poland was partitioned, and Empress Maria Theresa died, and Struensee was executed. America became independent, and the united French and Spanish forces were unable to capture Gibraltar. The Turks locked up General Stein in the Veteraner Cave in Hungary, and Emperor Joseph died also. King Gustavus of Sweden conquered Russian Finland, and the French Revolution and the long war began, and Emperor Leopold II went to his grave too. Napoleon captured Prussia, and the English bombarded Copenhagen, and the peasants sowed and harvested. The millers ground, the smiths hammered, and the miners dug for veins of ores in their underground workshops. (pp. 94-95)

If interested, we can read individual life histories of all of the rulers in this story for they have been considered paramount in the making of history. We can read about the struggles of the nations in this tale, but not about the ordinary people who inhabited those nations. The everyday lives of the millers, the peasants, the smiths, and the miners (not to mention their wives) are collectivized into verbs describing their occupations, and so their unique circumstances are lost. Also lost are the sense and meaning derived from national political events in the long life of the intended bride or of the other "common folk."

Therein lies the historical and anthropological sense of life history research: rewriting history to include the marginal and individual points of 
view instead of only "the vantage point of those who have had charge of running-or attempting to run-other people's lives" (Warren, 1982, p. 218). Life history research has therefore been a powerful methodology for feminist researchers who are attempting to gain a sense of women's history from journals, diaries, and oral narratives (Gluck \& Patai, 1991; Reinharz, 1994; Shostak, 1992). Life history could prove an effective addition to educational research by recording the lives of other disenfranchised groups that affect the educational milieu: teachers and administrators who, more than policy, collectively form the culture of schools and classrooms (Smith, 1994), students in classrooms, support staff, paraprofessionals, and, as in my research, students or parents not speaking the dominant language. The inclusion of marginal points of view can change or modify theory.

Frisbie (1982), for example, reviewed ethnographic and life history research looking for portraits of traditional Navajo women. Although her purpose was not to compare the two methodologies, she found significant differences. Although the ethnographies (often written by male researchers) documented only male participation in religious ceremonies and cattle-raising, the life histories made it evident that women were responsible for educating young men about these activities, and therefore had a role to play in them. Frisbie also notes that the life history approach documented unobservable, marginal, or unusual events, such as males engaging in weaving. In reviewing life histories, Frisbie noted such things as:

worries, as children about abuse, exploitation, or neglect; as adults, about winter hardship, loneliness, mishaps during pregnancy and childbirth, snake bites, pain from hard work or over work, loss of mind, Hand Trembling sickness, and other illnesses of self and others. (p. 20)

Clearly this challenges the theory that only males engage in these activities; women may not themselves engage in religious ceremonies or cattle-raising, but they transmit knowledge about them to their sons.

To this choir that includes marginalized voices can be added the attempt to collect histories of (sub)cultures that no longer exist, or to freeze-frame societies that are in danger of disappearing, tellingly referred to as "salvage ethnography" (Kirshenblatt-Gimblett, 1988, p. 139). According to Morin (1982), French ethnologists have been creating oral archives not out of methodological commitment to life history research, but in "a last ditch effort to salvage a cultural heritage" (p. 20). This has been one goal of Gmelch (1992) in recounting the life history of Nan Donohoe, a traveling person from Ireland, and of Bertaux and Bertaux-Wiame (1981) in their life history of French artisan bakers. It is also a personal goal for me in wishing to document the life histories of my husband's grandmothers, island women who have endured attempted linguicide, cultural imperialism, two world wars, 
and one occupation, and one of whom, for all she has witnessed, remembers most the first time she went to a big city and saw large plate-glass windows.

Recording alternative (sub)cultures, particularly those that do not have written archives of their own, has also been a principal motivation for anthropologists in the postcolonial present. Today no one any longer believes that nontechnological cultures are primitive outposts representing infancy in the development of civilized man; however, the anthropological urge to explore other ways of making sense of our humanness has supplanted the colonialist desire to know where we came from.

Related to the desire to reclaim history is what Camargo, da Rocha Lima, and Hippolito (1985) have argued is the need for nations emerging from the confines of colonization "to reach a deeper sense of identity and the particular problems of their own people" (p. 41). For this reason, life history research in Latin America is heterogeneous and not overburdened by methodological concerns. Life history research in Latin America both helps to forge the indigenous identity and to inform postcolonial policy and practice, with important implications for both the indigenous and immigrant or refugee populations of the industrialized West.

In the field of education in general, and ESL in particular, researchers and practitioners need to take responsibility for ensuring that Other histories are recorded, and that these histories inform policy and practice. Each generation of immigrants, each immigrant, comes to Canada for a different reason, leaving a changing social context and arriving in a changing social context. In the turmoil of forging new lives and new identities for themselves, they cannot be expected to record their stories and experiences for posterity in English (although, amazingly, a few have). As immigrants come to Canada, they help to create a new culture, both in ethnic communities and in the wider social context. Even one life history could add depth of knowledge to our understanding of social change, yet generations of histories of immigrants are lost because there is no time, ability, or opportunity to record them. When these marginal histories are lost, the cultural connections and sense of personal place in history are denied to future generations.

Finally, Said commented on what may be the most important benefit from life history research in ESL, rejection of the notion of a single identity:

If you're an exile ... you always bear within yourself a recollection of what you've left behind and what you can remember, and you play it against the current experience. So there's necessarily that sense of counterpoint. And by counterpoint I mean things that can't be reduced to homophony. (Marranca, Robinson, \& Chaudhuri, 1991, p. 43)

Said goes on to explain that the exile does not want to be able to reconcile the identities, but to hold them together. Life history text, being simultaneously a personal disclosure and rehearsed public performance (Dégh, 
1988), being both narrative and co-constructed, can embrace this polyphony and multiple identity as other research voices do not. Crapanzano's (1980) life history of Tuhami, for example, weaves together interpretation, narration, and incantation, representing the difference in Tuhami's identification with the events in his life at various times. My collection of life histories of first language loss incorporates several forms of narration, multilayered interpretation, and performance text, all of which have different voices. Such fusion may be more representative of the immigrant or refugee experience than one portraying a single cohesive identity.

Challenging and informing theory. On some occasions life history research has not only enriched understanding, but has challenged, recast, and/or informed prior theory. Josselson (1995) has pointed out that,

narrative approaches also force us to supersede dichotomies. People are not either introverted or extroverted, field-dependent or field-independent, or this or that. Dichotomous thinking eliminates the inner contradiction that is intrinsic to human personality. Because people are composed of a dialectic of opposites, the self is inherently dialogic. (p. 35)

Doing life history research means that the research participant may present profoundly conflicting views, and the research need not choose between them. In my research on language loss, for example, one participant fervently believed that her parents should have maintained the first language in the home so that she would not have lost it, but she equally fervently believed that all immigrants should be obliged to adopt the use of English in the home so that teaching ESL in schools would become unnecessary. Questioned about this contradiction, she said she believed both, that she would wait until my research was complete before deciding on an informed preference.

One example of overturning theory is provided by Turner's (1980) life history of Dan, a mildly retarded man advocating against the underestimated abilities of retarded people. After approximately one year of study, something (he doesn't say what) prompted Turner to administer psychological tests to Dan. According to these tests, Dan was of normal intelligence. The life history, which had been entirely framed in Dan's "retarded" subjectivity, was then retold from within a different identity. For example, Dan reported writing stories about rocks when he had thought himself retarded, yet he later admitted that his "stories" were articles published in Earth Science Magazine. Turner's research attests to how our view of our own life histories changes according to our perceptions of our identity.

Other examples have challenged theory. Fischer (1983), for example, explains how life history data caused her to rework the assumption that the mother-daughter relationship was dyadic when in fact the relationship was triadic, the mother and daughter forming a "conspiratorial alliance" (p. 34) 
against an "other." Thompson (1981) cites several examples, including reversal of the traditional assumption that the nuclear family is a modern postWW II phenomenon. Nelson (1992) found that Vermont rural schoolteachers did not always retire when they got married or pregnant, were often "liberated" in terms of role reversal in their married homes, were plagued by sexual harassment and intimidation from administrators and students, and were not always supportive of the move to graded schools, from which she concluded "public history often ignores minority views" (p. 185). Casey (1992), looking at teacher attrition, found that women who left the profession often did not see themselves as having left the educational field, but as having left the system.

There are many implications for ESL research. Schmidt's (1983) famous case study of the noninstructed language development of Wes, a 33-year-old Japanese man increasingly interested in immigrating to Hawaii, for instance, could have benefited from a life history perspective. Schmidt began the study by assessing Wes in terms of a variety of social and psychological distance factors, including age, formal English study, language aptitude, communicative need, interaction (type and amount), social dominance pattern, similarity of cultures, attitude, intended length of residence, culture shock, empathy, inhibition, motivation, and preferred learning style. With the exception of motivation for formal language study and similarity of the cultures, all the social and psychological factors were judged as potentially facilitative of English language acquisition. Over a three-year period of observation, Wes showed increased ability to engage in sustained conversations in English; however, his overall grammatical control of English did not improve at all. Schmidt therefore concluded that Schumann's 1978 acculturation model, in which a lesser degree of social and psychological distance from the target language group is the primary consideration for greater linguistic facility in the target language, is inaccurate.

Life history research may have informed this study in several ways. Although Schmidt (1983) devotes considerable attention to social and psychological distance as defined by the variables listed above, insufficient attention is given to Wes' life before his decision to leave Japan, during which time, it must be noted, his social and psychological distance developed. A life history approach in this case study would have attempted to reconstruct Wes' acquisition of Japanese, his first contacts with English, recollections of prior learning experiences, educational choices (particularly important as Wes left school at age 15), the decision to leave Japan, the critical events in Wes' life, parental attitudes toward foreigners, his apparent decision not to marry, and all other factors that eventually led Wes to the point at which he immigrated to an English-speaking country. Analysis of the life history would look at (a) the narrative form and templates used by Wes, (b) the sense and meaning he made of learning English in his life, (c) the ambivalence he 
displayed toward communication in English, and (d) whether a similar ambivalence existed in other contexts. In short, life history research would have cast a wider net, perhaps challenging and informing the notions of social and psychological distance in ESL instead of challenging whether they play a role in second language acquisition.

The case study of $\mathrm{CJ}$, an exceptionally good second language learner, conducted by Obler (1989), could also have benefited from life history research. More retrospective and reflective than Schmidt's (1983) study of Wes, this case study attempted to correlate a number of psychological and social factors with later success in learning several languages in postpuberty. CJ was interviewed about his language learning history and general background, including development, family history, school academic performance, parental expectations, and interactions, and was administered a series of psychological, intelligence, and neurophysiological tests.

Several of the items mentioned in the case study seem to warrant a life history approach. Obler (1989) reports that CJ believed his homosexuality to be particularly significant to understanding his language facility, but herself reasons why this may be so instead of reporting CJ's own understanding. CJ is a twin, yet there is no mention of whether he and his twin shared language ability, or whether they developed their own language. He is left-handed, reads laboriously, is poor at sports, lived in several foreign countries, has a maternal grandfather who was schizophrenic, and describes himself as a maverick. All these factors, if worth reporting, are worth exploring for their impact, real or perceived, on the second language learning of one individual. Moreover, the first-person reports given by $\mathrm{CJ}$ may benefit from augmentation by third-party reports, written documentation, and analysis of narrative form and function. In other words, many of these factors seem fundamentally linked to personality and identity; language is also so linked.

\section{Comprehensive $(\mathrm{Re})$ Interpretation}

One of the most exciting benefits of life history data is its comprehensiveness. This allows the life history to be interpreted by the researcher or others in many different ways at different times in the light of new theory and new insights. A good example is provided in Shaw's (1930) famous life history entitled The Jack-Roller: A Delinquent Boy's Own Story. Shaw's intent was to narrate the life of the title character, Stanley, in terms of "the essentially human aspects of the problem of delinquency" (p. 17). When reading the narrative, however, it is also possible to look at language conflict and to evaluate Stanley from a linguistic or language acquisition perspective (B. Mohan, personal communication). The villain in Stanley's narrative is his stepmother who abused him, starved him, cheated him, and encouraged him to steal. Yet halfway through the life history Stanley claims that "She could only speak her native tongue, which was Polish, and what little I understood 
meant that she was glad to see me at home again" (p. 82). Cast in a different analytic light this life story becomes a study of familial language conflict resulting in loss of parental control in an immigrant family. Additional insights could be gained from analysis of such emergent themes as domestic violence, gender roles, sexuality, as well as from analysis of the narrative form, the guiding metaphors, myths, and "cognitive templates" (Luborsky, 1987) employed by Stanley in the disclosure of his life.

In addition to the future potential of life history in ESL research, considerable knowledge could be gained from comprehensive reinterpretations of previously researched life histories in light of some of the social, psychological, and cognitive variables widely understood to affect second language acquisition. Analysis of the form and content of life histories could lead to greater understanding of aptitude, motivation, anxiety, personality, self-esteem, risk-taking, empathy, inference-making, the function of input, latent learning, psychological distance, cognitive style, learning strategies, inhibition, and language maintenance and loss, and could also lead to much deeper understanding of the process of language socialization. The life histories of first language loss that I have collected can be analyzed in terms of family relationships, school relationships, self-esteem, immigration status, motivation to integrate or assimilate, second-language skill, generational immigration to Canada, abuse, culture shock, negotiation of identity, parentchild conflict, or any of a number of other perspectives.

\section{Historical Clarity}

One of the problems with much social science research is that it is contemporaneously grounded, that is, "the structural and psychological variables have a timeless quality" (Elder, 1981, p. 108). Yet as Kárpáti (1981) points out, the meaning of a particular social class and the feeling toward that class may change over time. To use a personal and local example, when I am asked now about the origin of my last name and reply that it is Russian, it is something different from when my relatives were asked the same question 35 years ago. When I chose not to take my husband's Japanese last name at marriage, I did not make the decision as a feminist, nor did I feel particular attachment to my unmarried identity, nor did I want to hide his ethnicity, but rather, given the times and my field of work, I did not want to be accused of co-opting his ethnicity for personal gain. Without life history knowledge, change in the constitution of this one variable in my life would be inaccessible information for my daughter and her children. Without the life history context, contemporaneously grounded research is "like a photograph, giving a good picture of people, but telling very little about the story" (Elder, 1981, p. 134).

There is much potential in terms of historical clarity for life history research to benefit other kinds of research. Through life history reflection we could access, in real-lived rather than political terms, what has been meant 
by the jargon that frames our research. In my field of research it is sometimes easy to forget that terms such as $E S L$, native language, mother tongue, bilingual education, refugee, immigrant, mainstreaming, multiculturalism, limited English proficient, and so forth are dynamic rather than static. Their meanings do change, in connotation and even denotation, over different configurations of time and space.

There is a twofold imperative for ESL in conducting research that acknowledges the historical aspects of our knowledge of second-language acquisition. The first has been persuasively argued by such researchers as Pennycook (1990) and Phillipson (1992), holding that the field of applied linguistics / ESL has been dominated by ahistorical, modernist research and has therefore failed "to acknowledge both culture as the primary signifying system by which we make sense of the world and language learning as taking place within relationships of power" (Pennycook, 1990, p. 12). This, such researchers argue, has led to an emphasis on proof rather than understanding, and on trying to establish causal relationships between variables when the variables themselves are not well understood. It has also led to a focus on how to teach English as a second language rather than what, or even whether, to teach.

The second implication is with regard to ESL policy development and implementation. Research needs to be historically grounded and contextualized in order for us to understand fully the effects of policy and in order for us to develop more equitable and beneficial programs. It is important to include a life history perspective in order to appreciate political decisions in human terms, particularly with respect to those people most affected by those decisions, instead of in legal, economic, or otherwise-empowered terms.

I could cite many examples of this from my research on language loss, but I choose only one. A Canadian-born Chinese woman who participated in my research project spoke about how different attitudes toward multiculturalism in Canada had influenced her life. Although during her childhood multiculturalism had meant tolerance for other races and ethnicities while they were becoming assimilated, it had come to mean respect for and celebration of racial and ethnic diversity. The result in her life was that she had grown up striving to become more "Canadian," to speak English, to "be white" in an environment where her efforts were lauded but patronized. As an adult in an age of enlightened multiculturalism, she is now doubly cheated because, having abandoned her heritage, she does not have the cultural knowledge to celebrate her ethnicity. This is important knowledge for educators and policy-makers who need to adopt the perspective explained to me by a native Cree-speaking participant in my language loss research: We have to take particular care in making policy because the impact of every decision will be felt most fully seven generations hence. 


\section{Invitational Texts}

A question Lather (personal communication) addresses while reading theory is "What are the invitational qualities of the text?" a question addressing the politics of accessible language and blurring the distinction between academic and popular culture (Blumenfeld-Jones \& Barone, 1997). KirshenblattGimblett (1988) points out that during the between-war heyday of the life history form, researchers were aware of, and reacted against, "the dry and faceless character of kinship charts, folktale annotations, typologies of pottery styles, and normative accounts of social organization" (p. 141). Life histories, by contrast, are accessible by nature, have literary and rhetorical appeal, and therefore have greater potential than some other forms of research to "reach more than captive student audiences" (Bertaux, 1981b, p. 42).

Although Burgos (1989) argues that we expect style in life stories and that private life such as sexuality, dreams, fantasies, and suffering are relatively absent from their texts, this claim is not borne out in much life history research. Life history research is fundamentally linked to social ills, crime and deviant behavior being two of the most fully explored phenomena in sociological and psychological studies. Gmelch (1992), for instance, claims that life histories cause the readers to identify with the subjects of the life history and that, therefore, their understanding of deviance, marginality, domestic violence, autonomy, poverty, and inequality is enhanced. At the very least, the reading of life histories gives such problems a human face. At best, the reading of life histories can engender respect and understanding for the strength of others. As Gmelch (1992) reminds us, "by allowing readers to see the 'other' as real people grappling with their imperfections and the untidy complexity of human decision making, life histories reveal the underlying humanity of all people" (p. 38). In this statement are noteworthy implications for ESL research.

Although we do not like to admit it, an immigrant's obstacle to learning English can often be racism, and second-language learners are often excluded from conversations because their English is deemed poor, their contributions thought jarring and strange, or because of unequal power relations (Peirce, 1995; 1997). It is difficult to learn to speak a language without someone to speak to. If studies of English language learners, or non-English speakers, were widely read and considered interesting, perhaps greater multicultural understanding would result.

In my own teaching experience I have worked with ESL students who were considered lazy, unprincipled, incorrigible, criminal, deviant, unfocused, antisocial, or otherwise socially impaired. Indeed, in purely western cultural terms they were lazy, unprincipled, incorrigible, and so forth. Most of the students had been interviewed (or interrogated by) probation officers, support workers, psychologists, counselors, social services personnel, and 
the police, as well as the teachers, administrators, and social workers they had encountered in a variety of school situations. Yet when these students worked with me to produce life histories, many of those people were surprised to discover that the students were focused; they had been working in a different cultural framework. For instance, a young man who had experienced cannibalism as a child did not place the same value on individual human lives as the people who had interviewed him. And when survival is on the line, it can be the mark of intelligence and strength to lie, to cheat, to steal, to inform.

In sum, one of the problems faced by people who do not speak the dominant language is that they cannot be subjectively understood and therefore can become nameless and faceless immigrants, thought of as a homogeneous mass rather than as multifaceted, unique, and pulsating humans. As Watson (1976) points out, "we know the richness and complexity of our own subjective awareness and when we compare this to the many tedious, dehumanizing accounts of life in other cultures ... we may feel an acute sense of disinterest and alienation" (p. 128). Representing a life history lends itself easily to the writing of an invitational text, what Denzin (1994) might call a "vital text" (p. 504; see also Richardson, 1994), which texts have a measure of market appeal and may promote tolerance, if not appreciation, of difference.

\section{Benefits for the Participants}

As we see, life history research can benefit ESL in numerous ways. The inclusion of marginalized voices, the chance to challenge and inform theory, the capacity to allow for comprehensive reinterpretation, the grounding in history, and the opportunity to create invitational texts have all examined how life history as a research methodology can supplement and expand existing knowledge. The following section turns to how life history as a research methodology can benefit the participants, both the researched and the researcher.

Being listened to. Kaplan (1982) collected life histories with a view to understanding the role of institutions in the life of drug addicts. He argues that what is gained by the storyteller in recounting her or his life is something "beyond treatment":

not many people are interested in hearing the addict's own story. Other addicts are, but often they themselves are too busy trying to get the "best deal possible" to have time to listen to, much less help to tell, another's story. Thus the addict often falls into isolation and loses contact with his or her own history. (p. 49)

A similar picture is painted by Shaw (1980). He relates that after having told his story three times, the narrator was pleased because it had enabled 
him to "set his thoughts in order" (p. 231), that is, to construct a coherent identity for himself.

In my own research on immigrant mothers' struggles with the tension between learning English and maintaining their first cultures for their children, I was surprised when one of the women I interviewed thanked me for listening to her. I wanted to understand more what she meant by this and so I asked her. She said, "My English, could you understand?" When I replied that I could, she continued, "You give me many confidence. I worry about talking someone about something. Afraid of maybe they can't understand what I was talking" (fieldnotes, May, 1994). Until that point I had not asked many questions; in fact, the mother had taken over the interview, asking for advice in regard to her children's schooling in Canada. I listened and I answered, thinking that the interview was ruined but that I should answer her questions. When she thanked me I realized that my benefit to her was not my knowledge about ESL, but my listening to her concerns framed in her own way. Moreover, I had given up, and therefore relinquished control, learning in the process to suspend my agenda and listen.

Ortiz (1985) claims that we are seldom called on to listen-"one of the most wonderful things about falling in love, of course, is that at last someone will let you talk about yourself in detail" (p. 111). We sometimes underestimate the value of our listening in the lives of other/othered people, because as researchers part of our role is to speak loud enough to be heard, to demand and receive an audience. In other words, one of the responsibilities of academics is advocacy work. Listening, of course, should precede advocacy, whereas fieldwork, particularly life history fieldwork, places a premium on listening.

Nor is listening restricted to the researcher. Bloom (1996) makes us aware that the storyteller is also listening to her or his own story, reflecting on the story, examining the self-representation in the story, and becoming aware of how "subjectivities fragment, change, and become transformed" (p. 193). Bloom has found in her work that this process can lead to greater self-knowledge for the both the researcher and the researched, as well as to enhanced understanding of the conditions necessary for change and growth.

Owing to this research agenda, the relationship between researcher and researched in life histories is intimate, not unlike a love relationship. This shared intimacy and collaboration is later carried into the analysis by the researcher. Even with transcripts, complete documentation of the performance of a life history is dependent on the researcher's recollection and desire to do justice to the narrator's story. During analysis, then, the life history context will continually make us "confront the violence done to other people's consciousness by imposing our own terms on it" (Thompson, 1981, p. 293). At the same time, because it is polyphonous and written in narrative, the life history method also permits a partial solution to this problem. We are 
able to include the storyteller's interpretations and emendations as well as our own "so that the evidence can still be read in their way as well as ours when the work is written up" (Thompson, 1981, p. 293). In ESL research, when the difference in interpretations because of cultural influence is added to those from personal influences, inclusion of the life history seems at least warranted, if not demanded.

Overcoming adversity. Burgos (1989) observed that a life history narrative almost invariably begins with the refusal of the norm and then "starting from this early experience of rejection, or marginality, $\mathrm{s} / \mathrm{he}$ becomes conscious of her/himself" (p. 35). The benefit of this for the narrator is recognizing the moments of adversity in one's life and the uses to which they can be put (Cohler, 1991). The psychological advantage for participants in life history research comes when the narrator recognizes patterns in his or her responses to adversity. This enables him or her to capitalize on responses that were advantageous and discard those that were not. Although this is a trademark of psychological therapy, life histories in clinical situations are marked by the presupposition of mental discomfort that the client finds overwhelming enough to seek help. In life history research, where no patient-expert relationship exists, the process becomes one of validation and endorsement of the narrator's life. As McRae (1994) has explained:

It is not just that someone was there to hear it through to the utter last word, but the act of telling was itself a healing thing to do. Memory is where the self is captive, specialized, intense, and unamenable to any disposition but its own. Viewed in this light, personal narrative is a source of empowerment because, in shaping it, one is able to acknowledge the self who stands revealed and to benefit one's sense of identity from this congruence. If identity is the opposite of anonymity, and if identity is strengthened through the self-narrative, then telling one's story is a means of becoming, just as much as is having story to tell. (p. 215)

Added to this not inconsiderable benefit, life history research in ESL involves passing the chalice of expertness to the immigrant, conferring on her or him all the dignity and respect that implies.

In a study of Cuban refugees, for example, Ortiz (1985) looks at overcoming life-threatening adversity, a type particularly relevant for that ESL research addressing trauma and post-traumatic distress. The first therapeutic benefit for the Cuban refugees was the validation of their experiences; because Ortiz chose to have all the narrators meet together to talk about their experiences, the refugees were able to validate and empathize with each other's experiences. The second benefit was the validation of their experiences and their struggles by an outsider, what Ortiz calls catharsis. The third benefit was "grounding in reality," by which Ortiz means explaining choices, 
decisions, and opinions to someone outside who looks on with a different cultural perspective.

Again, I could cite many examples from my research, but I refer only to one. While I was engaged in the first language loss research, I came across a common misconception that people had lost their first languages because they were stupid, or poor at languages, or in some other way deficient, even when their life experiences had proven to them that they were not stupid, that they were highly capable, highly successful adults. As one woman put it, they wondered, "What's wrong with me that I lost this language?" (fieldnotes, July, 1995), a feeling that was echoed by the principal of a high school (with over $50 \%$ ESL students) who suggested that people lost their first languages because they were stupid. I spent a lot of time during the research process reassuring narrators that they were not stupid, that there was nothing wrong with them, that other people had similar experiences. Because I was lucky enough to be invited onto a provincial radio broadcast, during which time many people, including the radio show host, talked about the experience of losing a language, I was also able to supply recorded "evidence." In this way I was able to provide not only validation of their experiences, but also a large, diverse, language loss community.

Benefits to the researcher. Although it could be argued that all benefits of life history research are researcher benefits, Morin (1982) has in the course of her article pointed out two interesting personal gains for the researcher. The first is the struggle involved in trying to view things from another perspective, that is, the attempt to understand and then represent the emic view. I understand this in two ways. First, researchers often live in a body of theory, grounding the lives they study in the theory instead of grounding theory within the lives. This situation has led Middleton (1992b) to comment that:

Studies that rely too heavily on academics' readings of texts can "bracket out" - that is, render invisible - the everyday conversations, experiences, and perspectives of people in the schools. It is possible to assume from a reading of some academic critiques of policy texts that these texts characterize teachers and school administrators as passive socialized puppets of the New Right. (p. 302)

By struggling with everyday realities and emic perspective in life history research, the researcher must confront and struggle to overcome the potential imperialism of academic theory.

The second way I understand this is in terms of my own life history interviewing of immigrant mothers. My struggle to understand, and theirs to be understood, resulted in flashes of perfect intimacy in shared understanding. These moments of epiphany, in which I could taste the words of the women I interviewed, reminded me that I am human first, woman second, and researcher third, and that I need to do research likewise. 
The second benefit referred to by Morin (1982) is that the researcher need not try to control variables, but instead can look at their intersections in one person. Although at first this might seem somewhat glib, it is powerful in an ESL context. Variables such as social class and ethnicity are difficult to define in a given social structure. When a research subject has lived in different classes and different ethnic constructions, it adds another layer of difficulty. For me at least it is liberating to think of describing emic perspectives of social constructs instead of struggling to make my own categories and understandings fit less imperfectly.

In short, engaging in life history research encourages reflexivity and a holistic concept of the self and others. It offers us a new lens for our social science glasses. Life histories encourage the inclusion of marginalized voices, multiple never-ending data analyses, historically grounded records, and the chance to document inaudible, unobservable subjectivities. Life history research has the potential to open new fields of inquiry (like lifelong meaning construction) and new approaches to analysis (Bertaux \& Kohli, 1984), as well as suggesting different ways of negotiating binaries in research, allowing for the representation of ambivalence. In turn all this will help ESL teachers and researchers to forge better understandings of who our students are, where they came from, and who we are in relation to them. The products of life history research can potentially be knowledge that will benefit antiracist education, multicultural understanding, and general classroom practice.

\section{What Are the Potential Pitfalls of Life History Research?}

A number of criticisms have been leveled at life history research, including, but not limited to, poor representivity and lack of verifiability. Other potential pitfalls such as a tendency to exoticism, problems with transcription and translation, and ethical concerns about the afterlife of life history documents have been opened by proponents of life history.

\section{Potential Pitfalls for Theory and Research}

Although I do not wish to defend life history against charges of a-representivity and a-verifiability, I summarize some of the defenses with which other researchers have responded. I then acknowledge some of the other problems encountered by researchers noting, however, that most of these issues are not unique to life history research.

Representivity. In response to concerns about life history's lack of representivity, a chorus of voices suggests (e.g., Kárpáti, 1981) that life history research should augment other research methodologies or that life history data be analyzed as corpora rather than in isolation. Farrarotti (1981) argues that the basic unit of life histories should be "primary groups" because 
each individual does not totalize directly a whole society, he totalizes it by way of the mediation of his immediate social context, the small groups of which he is a part; for these groups are, in turn, active social agents which totalize their context etc. Similarly, the society totalizes every specific individual by way of mediating institutions which focalize it with increasing specificity toward the individual. (p. 23)

In other words, we acquire agency as members of a primary group while at the same time we are socialized by that primary group. Farrarotti, however, was primarily concerned with dialectical reasoning in analysis, and finished his article with a call for considering how it is theoretically and methodologically possible to research the life history of a primary group. Bertaux (1981b) and Bertaux and Bertaux-Wiame (1981) in the same volume suggest one practical alternative. They argue that after collecting approximately 30 life histories from artisan bakers in France, a "saturation of knowledge" (Bertaux, 1981b, p. 37) was reached. They feel this indicates a kind of representivity in their understanding of sociostructural relations. In my own language loss research, I decided to work with a commonsense understanding of this saturation of knowledge. After completing 21 life histories with individuals from various backgrounds and of various ages, I realized that I was no longer uncovering an abundance of themes that resonated throughout the life histories, but rather was engaged in collecting individual, unique, and local stories. Although each life history added new layers of understanding, new contexts, and new foci, the more generalizable partial truths had largely already made themselves apparent.

Watson (1989) also points to the importance of representivity in eliciting life histories in anthropology, suggesting that the more life histories we have for a cultural group, the more insightful our analysis of them. He explains that in his life history of Blanca, a Guajira woman, he assumed that her insights into the nature of evil, corruption, and responsibility were unique, but later realized other Guajiros had similar views.

Other researchers are involved in looking for other ways of obtaining greater representivity by triangulation and comparison in life history research. Woods (1985) and Middleton (1992b), both working with educators, and Kouritzin (1997, 1999, in press) all use an emergent-theme approach to understanding volumes of life histories focused on specific questions or events. Dex (1991) suggests quantifying life histories, arguing that the quantitative versus qualitative binary has broken down in research. Gagnon (1981) suggests going to a corpus of life histories with an a priori question and then looking for answers. In essence, then, the focus on uniqueness in life history research does not preclude a search for universals.

Verifiability. Questions of verifiability in subjective research seem to come from a feeling that life story narrators will not tell the truth so much as try to justify their own actions to an audience. Despite Smith's (1994) claim that 
"present-day scholars often see truth as less than granite" (p. 292), this has led to a general distrust of life history narratives and the prevailing belief that "the more damaging the evidence given by a narrator against himself the more honest it is likely to be" (Shaw, 1980, p. 231).

Woods (1985), a researcher concerned with the problems of reliability and representivity, believes that there is a twofold potential for dishonesty in life history research. He argues that narrators (a) might not tell the truth, or (b) might tell the truth as they see it in the present tense. This view may not correspond to what they felt was the truth at the time. This second "problem," I would argue, is unavoidable in any research involving questions about past events (i.e., virtually any research involving questions); understandings and perceptions of those events will always be framed in terms of the subject's present-time perceptions. Nor would it necessarily be desirable to escape this context-boundedness. Josselson (1995) points out:

Narratives select the elements of the telling to confer meaning on prior events-events that may not have had such meaning at the time. This is a narrative transposition of Kierkegaard's famous statement that we live life forward but understand it backward. In understanding ourselves, we choose those facets of our experience that lead to the present and render our story coherent. Only from a hermeneutic position are we posed to study the genesis and revision of people making sense of themselves. (p. 35)

I would add that it is the present use of those events that is of importance to social science researchers who are not so much interested in what people have experienced as in what the people have understood of their experiences.

If we discount postmodern views that truth does not exist and therefore cannot be told, we can look to Kaplan (1982) to address the first of Woods (1985) concerns (above). Kaplan feels that the researcher's intentions will affect verifiability. In potentially punitive situations, the life history narrators have more to lose, and therefore more to gain by misrepresenting themselves. Kaplan argues that,

If one's listening interest was dominated by the wish to help the story teller become more adjusted to society instead of allowing him to develop further and get out his own story, the quality of the dialogue would change and the stories become more varied, deformed, and deceitful. (p. 43)

Perhaps intentionally' deceitful stories are as revealing as completely truthful accounts. If men and women choose to lie about past events, they must have a reason to lie, and then they must live out the reality forced on them by that lie. 
We can also take the view of Linde (1993). Focusing on life stories, which she takes to be all the stories, chronicles, and explanations offered by an individual over the course of a lifetime, she criticizes approaches that look for facts about what really happened rather than acknowledging that the life story necessarily always changes:

A life story necessarily changes constantly-by the addition of stories about new events, by the loss of certain old stories, and by the reinterpretation of old stories to express new evaluations. We change our stories at least slightly for each new addressee as our relation to that addressee changes; we reshape stories as new events occur and as we acquire new values that change our understanding of past events; and we change our stories as our point of view, our ideology, or our overall understanding changes and reshapes our history. (p. 31)

In my own work I have found this approach to be ultimately preferable. Because of the type of questions that educational research tends to explore, because of stringent moral and ethical guidelines including respect, confidentiality, and acceptance (Measor \& Sikes, 1992), and because life history research generally demands work with voluntary participants, there is little perceivable benefit for the participants in lying or misrepresenting one's story. With the exception of cases of participants' intentional misrepresentation (Measor \& Sikes), working with the assumption that any discrepancies in accounts are due to a change in context and a change in temporal location maintains the integrity of the researcher-participant relationship and opens a new window on the project for the researcher and participant to explore (gently).

Exoticism. Given a choice between writing a life history of the accountant who lives down the hall from me or the men in cars selling drugs under my bedroom window, I would probably choose the dealers. Although I would argue that drugs are a social evil and that I could therefore do more beneficial research by developing social knowledge about criminal activity, I would only be telling part of the truth. I am more interested in the deviant, the macabre, and the criminal, thinking that they will have better stories to tell. This is what is meant by exoticism.

Morin (1982) explains that the focus in life history research in anthropology has shifted from the other "out there" to the other in our midst, that is, "from far flung exoticism to proximate exoticism where distance is created, simultaneously through history and subject matter" (p. 6). She raises concerns about trying to record ways of life that are disappearing in the same way that "life history mummified the Amerindian in his original 'primitivity' such as the anthropologist wished to represent it" (p. 12). Focusing on the exotic reinforces stereotypes of the Other. When we have chosen life history narrators because of their difference from ourselves, we then 
must look for validation of our a priori category Other. Working in ESL, the differences between $u s$ and them are often visible, and validation of their otherness comes from difference in racial characteristics. ${ }^{10}$

Although some researchers might argue that "working the hyphens," by which is meant "construct[ing] texts collaboratively, self-consciously examining our relations with/for/despite those who have been contained as Others" (Fine, 1994, p. 74) has rendered this problem less acute than in our "deeply colonial" (p. 75) past, Fine herself most eloquently troubles the notion of less exotic texts:

Whether Othering is produced "on" or "for," qualitative researchers need to recognize that our work stands in some relation to Othering. We may self-consciously or not decide how to work the hyphen of Self and Other, how to gloss the boundaries between, and within, slippery constructions of Others. But when we look, get involved, demur, analyze, interpret, probe, speak, remain silent, walk away, organize for outrage, or sanitize our stories, and when we construct our texts in or on their words, we decide how to nuance our relations with/for/despite those who have been deemed Others ... Our work will never "arrive" but must always struggle "between." (pp. 74-75)

There is no resolution to this problem. "Othering," not whether we do it, but how and to what ends, is the postcolonial dilemma.

\section{Potential Pitfalls for the Participants}

Translation and authorship. When we tell the stories of others, creating a text from oral narration and other documents, who does it belong to? Indeed, who wrote it? More to the point, "What do local people get from the outsider's view that they do not get from the insider's?" (Blackman, 1992, p. 58). These are difficult questions that are, as Keesing (1992) points out, made doubly difficult when an anthropologist translates from one cultural world to another. Life history research in an ESL context adds to this yet another layer-the translation of a life lived largely in a different language into the discourse genres and syntax of another language. Can we, do we even try to, negotiate the cultural chasm and write their stories as we think they might write them? Is "the task of the translator" to find "that intended effect upon the language into which he is translating which produces in it the echo of the original"? (Benjamin, 1968, p. 76). Is it, as Swantz (1996) writes, a kind of "cultural arrogance ... to study the people of another culture as a kind of specimen without ever asking them what they themselves wanted to find out or without discussing with them the goals of the study" (p. 124), by which I mean not just the goals of understanding, but also the goals of academic reward? 
Kirshenblatt-Gimblett (1988) also asks us to "consider the implications of listing the name of the anthropologist on the title page and spine of the book, but embedding the name of the narrator of the life history in the title of the book" (p. 142). She points out that there is a curious tension between identifying the anthropologist (or researcher) as the author, although he or she remains silent throughout conventional life history texts. This practice implies that the researcher is quoting the life history narrator, privileging the quoter over the quoted. It is also somewhat dishonest given the heavy editorial hand that Oring (1988) demonstrates, and that I have found, needs to be applied in writing the life history as text (for a complete discussion of researcher writing, see Kouritzin, 1997).

As Clandinin and Connelly (1994) point out, "raw sensory experience" (which I take to mean verbatim transcription or simple translation from one context to another) is, "if not meaningless, next to it" (p. 415), and the opposite, the "current disposition toward studying texts rather than people and their experience" (p. 415) that removes experience and is therefore equally meaningless, has left researchers trying to negotiate a middle ground where experience is recognized as being both temporal and storied. But such recognition is in itself a difficult problem for which there is no readily apparent solution. Currently, for example, I am grappling with how to write the life history of one young man who lost his first language and remains semiliterate in English. I am committed to writing in the first person, yet if I remain true to his words, telling his story with bravado and disdain, I worry that the role of the loss of his first language will be overlooked, and that he will be judged by his acts of violence. I also struggle with editorial decisions. Leaving his (and the other life history narrators') grammatical inconsistencies intact runs the risk of rendering his story picturesque (if not burlesque), whereas editing his account fails to illustrate his poor verbal skills. Moreover, as "story is ... neither raw sensation nor cultural form," but rather "both and neither" (Clandinin \& Connelly, 1994, p. 415), I remain juxtaposed between the desire to write in the cultural form of text and the desire to adhere as closely as possible to his words and his experience. Life histories such as this seem to demand a different kind of textual structure, one that is polyphonous while still retaining its narrative form, one that is analytical while still being invitational, one that defies my attempts to re/present. I have abandoned this story now, at least for the time being, unable to understand how to best follow the advice given by Denzin (1986): "We do not own the lives and the stories we tell. They are lent to us, given provisionally, if they are given at all" (p.17).

The Afterlife of Research

Concerns about the afterlife of life history research are similar to those in anthropological or educational ethnography, although perhaps more devas- 
tating in their import because they are that much more singular and personal. Many of the questions about the afterlife have been raised by Patai (1991) who, in writing the life story of a Brazilian woman, admits she has no answers:

Did she, on that day, imagine that I would describe her appearance and the poverty of the house? Did she have an inkling that the food she served me might become part of her story, that everything about the episode might in turn be served up to readers far away? How would she have felt about it if she had known these things? Would she have recognized herself in my sketch of her? Might she have thought that I had portrayed her weaknesses more than her strengths? Would she have felt betrayed? Used? And do these things matter? (p. 140)

The ethical concerns that Patai wrestles with in her article have to do with the intensity of the life history interview and the danger of textualizing intimate revelations for public consumption. The ethical concerns that I deal with include whether to admit that I did not like one of the life history narrators I worked with, whether to use a pseudonym for a man who wanted to be "outed" in my research, but who had told me many potentially damaging details, whether to discuss the problem with a (male) storyteller who seemed to be becoming inappropriately attached to me (female). In recording life histories, when we become uncomfortable with the kinds of "data" we are uncovering, we must constantly remind ourselves that no other form of research is innocent either.

Blackman (1992) reports that confusion may be caused by the unfamiliar research text. Community members who read the life history of a Haida woman did not understand what was narration, what analysis, and what interpretation. Therefore, Blackman's commentary was read as part of the life history and interpreted by some members of the narrator's community as bragging. This points not only to the afterlife of research for participants because of what they have disclosed, but also to an afterlife that results because of how the story is told. We cannot assume a sophisticated consumer of life histories, a consumer who, for example, is able to engage with questions about the nature of the narrator's experience, the context of narration, the reader's own experience, and the context of such reading (the "levels of experience" suggested by Clandinin \& Connelly, 1994). Granted we are able to, and should, speak of our own investment in the research project, our trials and errors, our experiences, our "tellings, livings, relivings, and retellings" (p. 418), but we need to remain cognizant that this practice does not eliminate, or even diminish, the possibility of misinterpretation. It does, however, enable polished readers to locate us; it places us at risk (at equal risk if we have done our work well); it allows readers to gain a sense of our 
professional and personal integrity; and it acknowledges the layers of experience that render a text.

Turning to the afterlife of disclosures, perhaps the worst consequence is that cited by Keesing (1992). He reported that Georges Condominas in 1971 related to the American Anthropological Association conference the afterlife of an ethnography he had written about the Mnong Gar of Vietnam. Bootleg copies of his ethnography were distributed to the US Special Forces units, who later tortured to death one of the narrators for information they thought he might have, and then razed the village he lived in. It is apparent that Condominas did not sufficiently guarantee the anonymity of his sources, but it is not always possible to do so. When the subjects of life histories are living, when they are in some cases recognizable, when they are not necessarily equipped to judge whether their stories will later damage them, what is the responsibility of the researcher? What is sufficient fictionalizing (Clandinin \& Connelly, 1994)?

A fear of fates similar to those of the Mnong Gar is recounted by Cuban refugees (Ortiz, 1985). Ortiz reports changing and reworking her final text to be absolutely certain that there would be no postpublication repercussions for family members remaining in Cuba:

It is hard for those of us who have never lived in a totalitarian society, recovering from bitter civil war, and besieged by acts of war and subversion from other countries to imagine the acts governments and individuals can actually carry out, and the atmosphere of terror such a situation can create. (p. 112)

To such problems I have no solutions. I can only reiterate that I am human first, a woman second, and a researcher third, and that I must work my research in the same manner. Being ethical according to institutional guidelines is not enough; I must also work from the heart.

In fact disclosure of the adverse experiences in one's life is always fraught with danger. Life history research should never be entered into lightly, or without caring, or with any pretense to objectivity. Entering a life history relationship stripped of our own subjectivities may nullify the benefits for our participants, and indeed put them at far greater personal and psychological risk than they would face in other kinds of research.

\section{Conclusion}

No matter what the methodology, it is essential for researchers to hold as a fundamental and guiding principle the safety and well-being of those we do research for, on, with, and among. Unlike the researcher role in more traditional methodologies, the life history researcher must remember to follow rather than lead, to listen rather than query, to hold back rather than probe. 
Life histories are unique in creating the possibilities for going beyond the conventional notions of what constitutes useful knowledge, for brushing with the muted subjectivities of those we research, and for revealing the transmutation of unobservable experience. From the researcher they demand greater reflexivity, more critical awareness of the role of the researcher, a commitment to social responsibility, and acknowledgment of one's own participation in an imperialistic enterprise. Life history, of course, is not the only methodology that leads researchers to acknowledge their assumptions, but it may be the only methodology that does so inherently. When the narrator begins a story, and that story winds itself through the a priori social categories of the researcher, race, class, language, culture, and history are bound together in multifarious ways that do not lend themselves easily to homogenous description. Life history, therefore, is perhaps a necessary addition to ESL research methodology, one powerful enough to gesture toward recording the complexity caused by the intersection of race, class, language, history, and culture that we face in our classrooms.

\begin{abstract}
Notes
${ }^{1}$ Although Smith (1994) discusses the use of biography in Professional Education, he points out that it "carries the same intellectual flavor of the feminist and minority perspective, finding voice among the disenfranchised, the powerless, or those with alternative visions" (p. 301; see also Butt, Raymond, McCue, \& Yamagishi, 1992). It is also noteworthy that educational biography appears to be predominantly concerned with teachers' lives and practices (Goodson, 1992; Shultz, 1997) rather than with those being taught. Exceptions are Barone (1997) and Kouritzin $(1997,1999$, in press).
\end{abstract}

${ }^{2}$ Several immigrant life histories written autobiographically (Hoffman, 1989; Rodriguez, 1981), or by researchers (Lieblich, 1993) contain elements of language acquisition or loss and education, but these are not primarily focused on teaching-learning English as a second language.

${ }^{3}$ As Denzin (1994) has pointed out, however, "in the social sciences there is only interpretation. Nothing speaks for itself" (p. 500).

${ }^{4}$ These may not always be desirable. In my own research I have sometimes found that life history narrators feel threatened by the thought of others interpreting their lives. Others have concluded that they would prefer not to include third parties because they value the relationship they have with me and do not want intrusion.

${ }^{5}$ The term interlanguage has a specific meaning in second language acquisition research, any point in a learner's second language development, a meaning that is played on here.

${ }^{6}$ Hall (Fine, 1994), speaking both about "truth" and about the presence of the other in narration, has written that "History changes your conception of yourself. Thus another critical thing about identity is that it is partly the relationship between you and the Other. Only when there is an Other can you know how you are" (p. 72).

${ }^{7}$ Member checks, meaning verifying stories and interpretations of research with the research participants before drafting final research papers, have been highly regarded in feminist research and are becoming commonplace also in all qualitative research. In my own research, experience has led me to make clear that member checks are an opportunity to comment, to modify, to double check to ensure anonymity, and to have the reservations or disagreements of the research participants put in print, but not an opportunity to retract everything that they have said. Shultz (1997) bravely recounts her struggles with member checks, especially when one of her research 
participants felt hurt by what she had written, a problem I have also encountered. Offering participants the opportunity to retract what they have said runs the risk of forcing the researcher to write only nice things.

${ }^{8}$ I have often found that the participants in my research have believed that I might be more powerful than I am, that I might be able to affect policies or practices that would improve the circumstances of their own or their family's lives. I need to make it clear to them that the only power I have is to help them make their voices heard.

${ }^{9} \mathrm{~A}$ conversation is generally not recorded or transcribed. The word conversation implies that the conversants have equal power relationships and equal responsibility to keep the flow of dialogue going. The social conventions of these interviews were clearly controlled by me, although I was amenable to negotiation and change.

${ }^{10}$ As Fine and Weis (1996) make apparent, layers are added when our others engage in othering, and, I might add, when people of mixed heritage "other" a part of themselves, thus denying their ethnic ancestry.

\section{Acknowledgments}

The author would like to thank Drs. Donald Fisher, Marion Crowhurst, Margaret Early, Patricia Duff, Norman K. Denzin, and Patrick Mathews, as well as TESL Canada's anonymous reviewers for their helpful comments on earlier drafts of this article. The author is, however, solely responsible for any errors.

\section{The Author}

Sandra (Sandie) Kouritzin is an assistant professor of TESL in the Department of Curriculum, Teaching and Learning at the University of Manitoba. Her research interests include first language loss, heritage language maintenance, narrative research, and language policy. She can be reached at kouritzi@ms.umanitoba.ca.

\section{References}

Bar-On, D., \& Gilad, N. (1994). To rebuild life: A narrative analysis of three generations of an Israeli Holocaust survivor's family. In A. Lieblich \& R. Josselson (Eds.), Exploring identity and gender: The narrative study of lives (vol. 2, pp. 83-112). Thousand Oaks, CA: Sage.

Barone, T.E. (1997). Among the chosen: A collaborative educational (auto)biography. Qualitative Inquiry, 3, 222-236.

Benjamin, W. (1968). Illuminations: Essays and reflections (H. Arendt, Ed. \& H. Zohn Trans.). New York: Schoken Books.

Bertaux, D. (Ed.). (1981a). Biography and society: The life history approach in the social sciences. Beverly Hills, CA: Sage.

Bertaux, D. (1981b). From the life history approach to the transformation of sociological praxis. In D. Bertaux (Ed.), Biography and society: The life history approach in the social sciences (pp. 29-46). Beverly Hills, CA: Sage.

Bertaux, D., \& Bertaux-Wiame, I. (1981). Life stories in the bakers' trade. In D. Bertaux (Ed.), Biography and society: The life history approach in the social sciences (pp. 169-189). Beverly Hills, CA: Sage.

Bertaux, D., \& Kohli, M. (1984). The life story approach: A continental view. Annual Review of Sociology, 10, 215-237.

Bertaux-Wiame, I. (1981). The life history approach to the study of internal migration. In D. Bertaux (Ed.), Biography and society: The life history approach in the social sciences (pp. 249-265). Beverly Hills, CA: Sage.

Blackman, M.B. (1992). Returning home: Life histories and the Native community. Journal of Narrative and Life History, 2, 49-59. 
Bloom, L.R. (1996). Stories of one's own: Nonunitary subjectivity in narrative representation. Qualitative Inquiry, 2, 176-197.

Blumenfeld-Jones, D.S., \& Barone, T.E. (1997). Interrupting the sign: The aesthetics of research texts. In J.A. Jipson \& N. Paley (Eds.), Daredevil research: Re-creating antalytic practice (pp. 83-108). New York: Peter Lang.

Borland, K. (1991). "That's not what I said": Interpretive conflict in oral narrative research. In S.B. Gluck \& D. Patai (Eds.), Women's words: The feminist practice of oral history (pp. 63-76). New York: Routledge.

Burgos, M. (1989). Life stories, narrativity, and the search for the self. Life Stories, 5, 29-38

Butler, S.J., \& Bentley, R. (1992). Literacy through lifewriting. English Quarterly, 24, 33-41.

Butt, R., Raymond, D., McCue, G., \& Yamagishi, L. (1992). Collaborative autobiography and the teacher's voice. In I.G. Goodson (Ed.), Studying teachers' lives (pp. 51-98). New York: Routledge.

Camargo, A., da Rocha Lima, V., \& Hippolito, L. (1985). The life history approach in Latin America. Life stories, 1, 41-54.

Casey, K. (1992). Why do progressive women activists leave teaching? Theory, methodology and politics in life-history research. In I.G. Goodson (Ed.), Studying teachers' lives (pp. 187-208) New York: Routledge.

Chanfrault-Duchet, M. (1991). Narrative structures, social models, and symbolic representation in the life story. In S.B. Gluck \& D. Patai (Eds.), Women's words: The feminist practice of oral history (pp. 77-92). New York: Routledge.

Clandinin, D.J., \& Connelly, F.M. (1994). Personal experience methods. In Y. Lincoln \& N.K. Denzin (Eds.), The handbook of qualitative research (pp. 413-427). Thousand Oaks, CA: Sage

Cohler, B.J. (1991). The life story and the study of resilience and response to adversity. Journal of Narrative and Life History, 1, 169-200.

Crapanzano, V. (1980). Tuhami: Portrait of a Moroccan. Chicago, IL: University of Chicago Press.

Cruikshank, J. (1990). Life lived like a story: Life stories of three Yukon Native elders. Vancouver, BC: University of British Columbia Press.

Dégh, L. (1988). Beauty, wealth and powier: Career choices for women in folktales and modern media. In T. Hofer \& P. Niedermiuller (Eds.), Life history as cultural construction/performance (pp. 13-47). Budapest: Ethnographic Institute of the Hungarian Academy of Sciences.

Delamont, S. (1992). Fieldwork in educational settings: Methods, pitfalls and perspectives. London: Falmer Press.

Denzin, N.K. (1986). Interpreting the lives of ordinary people: Sartre, Heidegger and Faulkner. Life stories, 2, 6-20.

Denzin, N.K. (1989). Interpretive biography. Qualitative research methods series 17 . Newbury Park, CA: Sage.

Denzin, N.K. (1994). The art and politics of interpretation. In Y. Lincoln \& N.K. Denzin (Eds.), The handbook of qualitative research (pp. 500-515). Thousand Oaks, CA: Sage.

Dex, S. (1991). Life and work history analyses. Sociological Review Monograph, 37, 1-19.

Elder, G. (1981). History and the life course. In D. Bertaux (Ed.), Biography and society: The life history approach in the social sciences (pp. 77-115). Beverly Hills, CA: Sage.

Farrarotti, F. (1981). On the autonomy of the biographical method. In D. Bertaux (Ed.), Biography and society: The life history approach in the social sciences (pp. 19-27). Beverly Hills, CA: Sage.

Fine, M. (1994). Working the hyphens: Reinventing self and other in qualitative research. In Y. Lincoln \& N.K. Denzin (Eds.), The handbook of qualitative research (pp. 70-82). Thousand Oaks, CA: Sage.

Fine, M., \& Weis, L. (1996). Writing the "wrongs" of fieldwork: Confronting our own research/writing dilemmas in urban ethnographies. Qualitative Inquiry, 2, 251-274.

Fischer, L.R. (1983). Sociology and life history: Methodological incongruence? International Journal of Oral History, 4, 29-40. 
Frank, G. (1979). Finding the common denominator: A phenomenological critique of life history method. Ethos, 7, 68-94.

Freeman, M. (1984). History, narrative, and life-span developmental knowledge. Human Development, 27, 1-19.

Frisbie, C.J. (1982). Traditional Navajo women: Ethnographic and life history portrayals. American Indian Quarterly, 6, 11-33.

Gagnon, N. (1981). On the analysis of life accounts. In D. Bertaux (Ed.), Biography and society: The life history approach in the social sciences (pp. 47-60). Beverly Hills, CA: Sage.

Gluck, S.B., \& Patai, D. (Eds.). (1991). Women's words: The feminist practice of oral history. New York: Routledge.

Gmelch, S. (1992). From beginning to end: An Irish life history. Journal of Narrative and Life History, 2, 29-38.

Goodson, I.G. (Ed.). (1992). Studying teachers' lives. New York: Routledge.

Hankiss, A. (1981). Ontologies of the self: On the mythological rearranging of one's life-history. In D. Bertaux (Ed.), Biography and society: The life history approach in the social sciences (pp. 203-209). Beverly Hills, CA: Sage.

Hofer, T., \& Niedermüller, P. (1988). Life history as cultural construction/performance. Budapest: Ethnographic Institute of the Hungarian Academy of Sciences.

Hoffman, E. (1989). Lost in translation: A life in a new language. New York: Dutton.

Josselson, R. (1995). Imagining the real: Empathy, narrative, and the dialogic self. In R. Josselson \& A. Lieblich (Eds.), Interpreting experience: The narrative study of lives (vol. 3, pp. 27-44). Thousand Oaks, CA: Sage.

Josselson, R., \& Lieblich, A. (Eds.). (1995). Interpreting experience: The narrative study of lives. Thousand Oaks, CA: Sage.

Kaplan, C.D. (1982). Addict-life stories: An exploration of the methodological grounds for the study of social problems, part I. International Journal of Oral History, 3, 31-50.

Kárpáti, Z. (1981). The methodological use of the life history approach in a Hungarian survey on mobility and urbanization. In D. Bertaux (Ed.), Biography and society: The life history approach in the social sciences (pp. 134-148). Beverly Hills, CA: Sage.

Keesing, R.M. (1992). Writing Kwaio life histories: Issues of authorship and politics. Journal of Narrative and Life History, 2, 39-47.

Kirby, S., \& McKenna, K. (1989). Experience, research, social change: Methods from the margins. Toronto, ON: Garamond Press.

Kirshenblatt-Gimblett, B. (1988). Authoring lives. In T. Hofer \& P. Niedermüller (Eds.), Life history as cultural construction/performance (pp. 133-178). Budapest: Ethnographic Institute of the Hungarian Academy of Sciences.

Kouritzin, S. (1994, June). Mothering in a second language: The need to divide identities. Paper presented at the meeting of the Canadian Society for the Study of Education, Calgary.

Kouritzin, S. (1997). Cast-away cultures and taboo tongues: Facelt]s of first language loss. Unpublished doctoral dissertation, University of British Columbia.

Kouritzin, S. (1999). Facelt]s of first language loss. Mahwah, NJ: Erlbaum.

Kouritzin, S. (in press). Immigrant mothers define access to ESL classes: Contradiction and ambivalence. Journal of Multilingual and Multicultural Development.

Linde, C. (1993). Life stories: The creation of coherence. New York: Oxford University Press.

Lieblich, A. (1993). Looking at change: Natasha, 21; New immigrant from Russia to Israel. In R. Josselson \& A. Lieblich (Eds.), The narrative study of lives (vol. 1, pp. 92-129). Thousand Oaks, CA: Sage.

Lieblich, A., \& Josselson, R. (Eds.). (1994). Exploring identity and gender: The narrative study of lives, vol. 2. Thousand Oaks, CA: Sage.

Lincoln, Y., \& Denzin, N.K. (1994). The handbook of qualitative research. Thousand Oaks, CA: Sage.

Luborsky, M.R. (1987). Analysis of multiple life history narratives. Ethos, 15, 366-81. 
Marranca, B., Robinson, M., \& Chaudhuri, U. (1991). Criticism, culture, and performance: An interview with Edward Said. In B. Marranca \& G. Dasgupta (Eds.), Interculturalism and performance: Writings from PAJ (pp. 38-59). New York: PAJ Publications.

McCrea, J.F.K. (1994). A woman's story: E pluribus unum. In A. Lieblich \& R. Josselson (Eds.), Exploring identity and gender: The narrative study of lives (vol. 2, pp. 195-229). Thousand Oaks, CA: Sage.

McMillan, J.H., \& Schumacher, S. (1989). Research in education: A conceptual introduction (2nd ed.). United States: Harper Collins.

Measor, L., \& Sikes P. (1992). Visiting lives: Ethics and methodology in life history. In I. Goodson (Ed.), Studying teachers' lives (pp. 209-233). New York: Routledge.

Mercier, L., \& Murphy, M. (1991). Confronting the demons of feminist public history: Scholarly collaboration and community outreach. In S.B. Gluck \& D. Patai (Eds.), Women's words: The feminist practice of oral history (pp. 175-188). New York: Routledge.

Middleton, S. (1992a). Developing a radical pedagogy: Autobiography of a New Zealand sociologist of women's education. In I. Goodson (Ed.), Studying teachers' lives (pp. 18-50). New York: Routledge.

Middleton, S. (1992b). Equity, equality, and biculturalism in the restructuring of New Zealand schools: A life-history approach. Harvard Educational Review, 62, 301-22.

Morin, F. (1982). Anthropological praxis and life history. International Journal of Oral History, 3, 5-30.

Nelson, M. (1992). Using oral case histories to reconstruct the experiences of women teachers in Vermont, 1900-50. In I. Goodson (Ed.), Studying teachers' lives (pp. 167-186). New York: Routledge.

Nunan, D. (1992). Research methods in language teaching. Cambridge, UK: Cambridge University Press.

Obler, L.K. (1989). Exceptional language learners. In S. Gass, C. Madden, D. Preston, \& L. Selinker (Eds.), Variation in second language acquisition volume II: $P_{\text {sycholinguistic issues. }}$ Philadelphia, PA: Multilingual Matters.

Ochberg, R.L. (1988). Life stories and the psychosocial construction of careers. Journal of Personality, 56, 173-204.

Oring, E. (1988). Generating lives: The construction of autobiography. In T. Hofer \& P. Niedermüller (Eds.), Life history as cultural construction/performance (pp. 179-211). Budapest: Ethnographic Institute of the Hungarian Academy of Sciences.

Ortiz, K.R. (1985). Mental health consequences of life history method: Implications from a refugee case. Ethos, 13, 99-120.

Patai, D. (1991). U.S. academics and third world women: Is ethical research possible? In S.B. Gluck \& D. Patai (Eds.), Women's words: The feminist practice of oral history (pp. 137-154). New York: Routledge.

Pennycook, A. (1990). Towards a critical applied linguistics for the 1990s. Issues in Applied Linguistics, 1, 8-28.

Phillipson, R. (1992). Linguistic imperialism. Oxford, UK: Oxford University Press.

Polkinghorne, D.E. (1991). Narrative and self-concept. Journal of Narrative and Life History, 1, 135-153.

Peirce, B.N. (1995). Social identity, investment, and language learning. TESOL Quarterly, 29, 9-30.

Peirce, B.N. (1997). Language, identity, and the ownership of English. TESOL Quarterly, 31, 409-430.

Reinharz, S. (1994). Feminist biography: The pains, the joys, the dilemmas. In A. Lieblich \& R. Josselson (Eds.), Exploring identity and gender: The narrative study of lives (vol. 2, pp. 37-82). Thousand Oaks, CA: Sage.

Richardson, L. (1994). Writing a method of inquiry. In Y. Lincoln \& N.K. Denzin (Eds.), The handbook of qualitative research (pp. 516-529). Thousand Oaks, CA: Sage. 
Rodriguez, R. (1981). Hunger of memory: The education of Richard Rodriguez. Boston, MA: Godine.

Schmidt, R.W. (1983). Interaction, acculturation, and the acquisition of communicative competence: A case study of an adult. In N. Wolfson \& E. Judd (Eds.), Sociolinguistics and language acquisition (pp. 137-174). Rowley, MA: Newbury House.

Shaw, B. (1980). Life history writing in anthropology: A methodological review. Mankind, 12, 226-233.

Shaw, C.R. (1930). The jack-roller: A delinquent boy's own story. Chicago, IL: University of Chicago Press.

Shostak, M. (1992). Nisa revisited. Journal of Narrative and Life History, 2, 19-28.

Shultz, R. (1997). Interpreting teacher practice: Two continuing stories. New York: Teachers College Press.

Smith, L.M. (1994). Biographical method. In Y. Lincoln \& N.K. Denzin (Eds.), The handbook of qualitative research (pp. 286-305). Thousand Oaks, CA: Sage.

Stacey, J. (1991). Can there be a feminist ethnography? In S.B. Gluck \& D. Patai (Eds.), Women's zoords: The feminist practice of oral history (pp. 111-120). New York: Routledge.

Stake, R.E. (1995). The art of case study research. Thousand Oaks, CA: Sage

Thompson, P. (1981). Life histories and the analysis of social change. In D. Bertaux (Ed.), Biography and society: The life history approach in the social sciences (pp. 289-306). Beverly Hills, CA: Sage.

Swantz, M. (1996). A personal position paper on participatory research: Personal quest for living knowledge. Qualitative Inquiry, 2, 120-136.

Turner, J.L. (1980). Yes I am human: Autobiography of a "retarded career." Journal of Community Psychology, 8, 3-8.

Van Manen, M. (1992). Researching lived experience: Human science for an action sensitive pedagogy. MI: Althouse Press.

Warren, C.E. (1982). The written life history as a prime research tool in adult education. Adult Education, 32, 214-228.

Watson, L.C. (1976). Understanding a life history as a subjective document: Hermeneutical and phenomenological perspectives. Ethos, 4, 95-131.

Watson, L.C. (1989). The question of "individuality" in life history interpretation. Ethos, 17, 308-325.

Wolcott, H.F. (1994). Transforming qualitative data: Description, analysis, and interpretation. Thousand Oaks, CA: Sage.

Wolcott, H.F. (1983). Adequate schools and inadequate education: The life history of a sneaky kid. Anthropology and Education Quarterly, 14, 3-32.

Woods, P. (1985). Conversations with teachers: Some aspects of life-history method. British Educational Research Journal, 11, 13-26.

Yin, R.K. (1994). Case study research: Design and methods (2nd ed.). London: Sage. 